\section{Año 2019-2020. urtea N. ${ }^{\circ} 31-32 . z k$.}

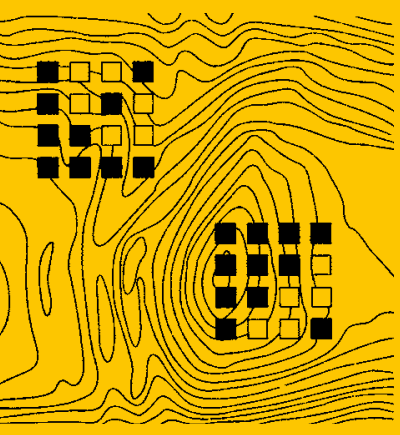

\section{TRABAJOS DE ARQUEOLOGÍA NAVARRA}

SEPARATA

\title{
Artziko aztarnategi erromatarra: 2020ko indusketa kanpaina
}

Oihane Mendizabal Sandonís, Ekhine Garcia-Garcia, Juan Mari Martinez Txoperena, Rafa Zubiria, Juantxo Agirre Mauleon

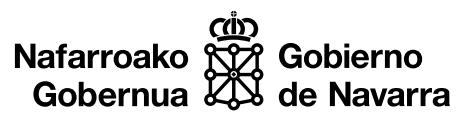

0000 


\section{Artziko aztarnategi erromatarra: 2020ko indusketa kanpaina}

Yacimiento romano de Artzi: campaña de excavación de 2020

The Roman site of Artzi: 2020 excavation campaign

Oihane Mendizabal Sandonís

UPV/EHU. Aranzadi Zientzia Elkartea

omendizabal@aranzadi.eus

Ekhine Garcia-Garcia

Aranzadi Zientzia Elkartea. SOT Prospecció Arqueògica

ekhinegarcia@yahoo.com

Juan Mari Martinez Txoperena

Aranzadi Zientzia Elkartea

txoperena@gmail.com

\section{Rafa Zubiria}

Aranzadi Zientzia Elkartea

rafzubiria@gmail.com

Juantxo Agirre Mauleon

Aranzadi Zientzia Elkartea

zuzendaritza@aranzadi.eus

DOI: https://doi.org/10.35462/TAN31-32.11

Ayudas a entidades locales para intervenciones en el Patrimonio Arqueológico y Paleontológico del Gobierno de Navarra.

Esker emateak: Indusketa kanpainan parte hartu duten boluntario guztiei eta bereziki Jose Javier Uriz, Garbiñe Lizeaga eta haien familiari. 


\section{LABURPENA}

Artziko aztarnategi arkeologikoa izen bereko parajean kokatuta dago nafar Aurrepirinioan, Artzibar/ Valle de Arce udalerriaren barnean, hain zuzen ere. Ibar horri zeharkatzen duen galtzada erromatarrari lotutako miaketa lanetan kokagunea identifikatu zuten, eta ondoren egindako ikerketa geofisikoek eta indusketa arkeologikoek haren karakterizazioa ahalbidetu dute. Haiei guztiei esker, eraikin multzo bat erregistratu da, eta horien artean bi erabilpen fase dokumentatu diren termagunea. 2020ko indusketa kanpaina terman oinarritu da eta hark izango zituen ezaugarriak ezagutzen informazio baliagarria eskaini dute.

Gako hitzak: aztarnategi erromatarra; Aurrepirinioa; termagunea.

\section{RESUMEN}

El yacimiento arqueológico de Artzi está situado en el paraje del mismo nombre en el Prepirineo navarro, en el término municipal de Artzibar/Valle de Arce. El enclave se identificó durante las tareas de prospección vinculadas a la calzada romana que atraviesa este valle y ha sido caracterizado gracias a los estudios geofísicos y las excavaciones arqueológicas realizadas posteriormente. Gracias a todos ellos, se ha registrado un conjunto de construcciones, entre los que se ha documentado un edificio de termas con dos fases de uso. Las campañas de excavación de 2020 se han centrado en la construcción termal que ha ofrecido información muy importante sobre las características que pudo tener.

Palabras clave: asentamiento romano; Prepirineo; complejo termal.

\section{ABSTRACT}

The archaeological site of Artzi is located in the area of the same name in the Navarre pre-Pyrenees, in the municipality of Artzibar/Valle de Arce. The settlement was identified during prospecting work linked to the roman road that crosses this valley. The remains had been characterised by the geophysical studies and archaeological excavations. Thanks to all of them, a group of buildings has been recorded, among which a thermal baths building with two phases of use has been documented. The 2020 excavation campaigns focused on the thermal building, which has provided very important information about its possible characteristics.

Keywords: Roman site; pre-Pyrenees; thermal complex. 
1. SARRERA. 2. 2020KO INDUSKETA ARKEOLOGIKOA. 3. ONDORIOAK. 4. BIBLIOGRAFIA.

\section{SARRERA}

Erromatar garaiko aztarnategia, ARC5 kodeduna, Artziko Ama Birjina parajean kokatuta dago, Nagore eta Zandueta herrien artean, Urrobi ibaiaren ekialdeko ertzean. Kokaleku honetan Artzi deitutako jaurerria zegoen garai batean (Iribarren, Larrea \& López-Mugertza, 2019, 82. or.), nahiz eta gaur egun jauregia, eliza erromanikoa eta beste etxe baten arrastoak besterik ez dauden ikusgai.

Paraje honen gainetik pasatzen den NA2040 errepideko eraikuntza lanen karira aurkitu zituen Juan Mari Martinez Txoperenak erromatar garaiko zeramikak mugitutako lurrean, eta hori izan zen ikerketa zabalagoari abiapuntua eman zioena.

Egungo informazioen arabera, erromatar garaiko galtzada ibaiaren mendebaldeko ertzetik igarotzen da, paraje hau Auritz eta Aurizberri artean kokatutako Zalduako aztarnategiarekin lotuaz. Testuinguru honetan, miaketa-zuloak burutu zituen Aranzadi Zientzia Elkarteak 2012. urtean. Saihesbidearen iparraldean kokatutako $2 \mathrm{~m} \mathrm{x}$ 2 metroko eremuan, erromatar garaiko zeramika, metal eta beira zatiak aurkitu ziren, nahiz eta ez zen inolako eraikuntza egiturarik ikusi (Agirre, Martínez \& Puldain, 2012).

Inguru honetan erromatar garaiko asentamendua egon zitekeelakoan, miaketa geofisiko bidez ikertu zen doktoretza tesi baten baitan (Garcia-Garcia, 2017). Honela, 2014 urtean miaketa magnetikoa burutu zen indusitako miaketa-zuloaren inguruan. Ondorengo urtean georradarra eta miaketa elektrikoa erabili ziren emaitza magnetikoetan oinarrituta definituriko interes gunean. Ikerketa honi esker ezagutu zen eremu horretan 
eraikin bat bazegoela, 20 × 5,5 metroko azalera duena eta 5 gelatan banatua, erdikoak absidea duelarik aldeetariko batean. Horrez gain, eraikinaren erdigunean kontraste magnetiko altuko elementuren baten presentzia detektatu zen, errekuntza ala burdinazko objektuen pilaketa izan zitekeena, eta gelatariko batek zoru zurruna izan zezakeela (Garcia-Garcia, 2017).

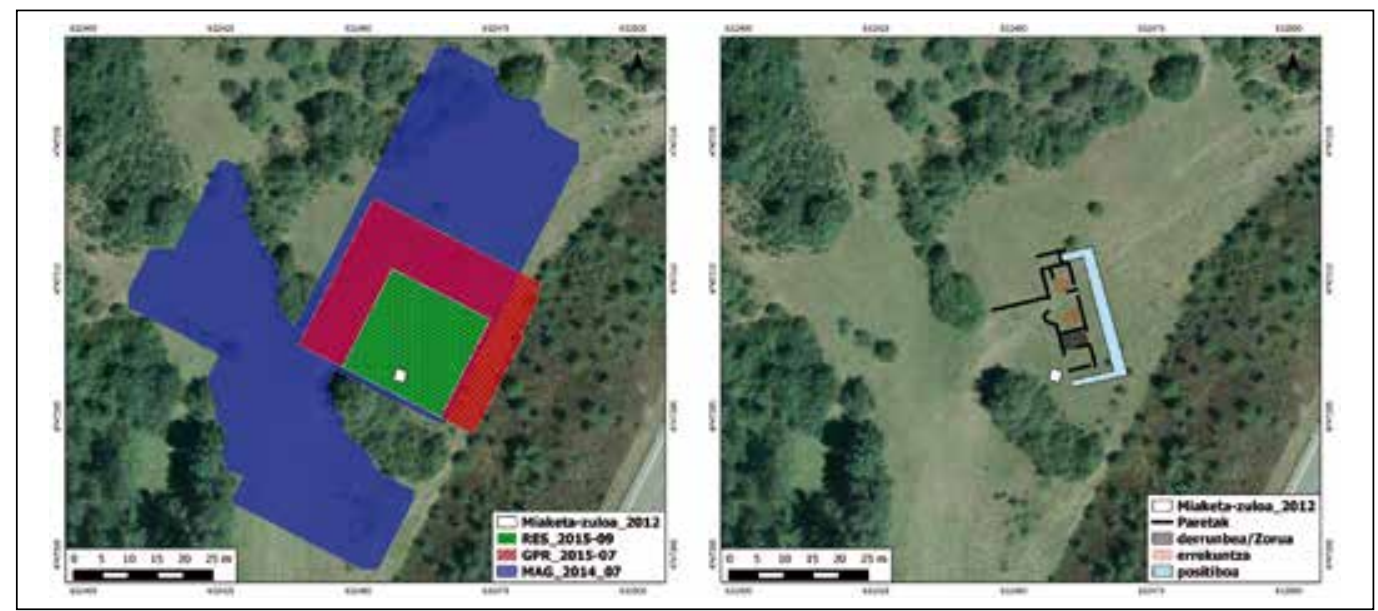

1. irudia. Ezkerrean 2014 eta 2015. urtean egindako miaketa geofisikoen eremuak eta eskuinean geofisikako emaitzen oinarrituz buruturiko interpretazio sintesia. Iturria: E. Garcia-Garcia, 2017.

Hurrengo bi urteetan indusketa arkeologikoak burutu ziren eraikinaren absidedun gelan, emaitza geofisikoak baieztatu asmoz. Esku-hartze horiek agerian jarri zuten geofisikak detektatutako eraikina terma-egitura bati zegokiola, bai eraikuntza materialengatik zein in situ aurkitutako pilaearengatik (Garcia-Garcia, 2017). Emaitza honetan oinarrituta inguruan eraikin gehiago egon zitezkeela ondorioztatu zen, eta miaketa geofisiko berriak antolatu ziren horien inguruko informazioa bildu asmoz.

2017an miaketa magnetikoa eta georradarra aplikatu ziren, eta gutxienez beste hiru eraikuntza-multzo deskribatzeko aukera izan zen (Garcia-Garcia, Sala \& Ortiz, 2017). Eraikuntza horien kronologia eta tipologia ezagutzeko asmotan, urte horretako indusketa kanpainan bost miaketa-zulo burutu ziren. Tipologia ezberdina erakutsi arren, bertan aurkitutako materialek erromatar garaian kokatu zituzten eraikin hauek. Horrez gain, indusketek argi utzi zuten kontserbatutako potentzia arkeologikoa aise nabarmenagoa dela jatorrizko eraikinean, besteetan eraikinen oinarriak besterik ez bai ziren aurkitu. Ondorioz, egungo informazioaren arabera hektarea inguru hartzen duen aztarnategi baten aurrean gaudela esan daiteke.

Aztarnategiaren testuingurua eta kontserbazio-maila ezberdinak karakterizatutzat emanda, hurrengo urteetan terma-egitura zabalean industeari ekin genion. 2018. urtean eraikinaren erdiko gela industen hasi zen, eta 2019. urtean gela hori agortu eta hegoaldekoa indusi zen. Lan horiei esker eraikinak gutxienez bi fase eta erabilera nagusi izan dituela baieztatu daiteke. Lehena, eraikin exentu batean berogailu sistemaz 
hornitutako terma azpiegitura lineal bati dagokio (Balmelle, 2001, 182. or.; García Entero \& Arribas, 2000, 89. or.). Orain arte daukagun informazioaren arabera praefornium edo labea eraikinaren iparraldean kokatua egongo litzateke eta, ondorioz, baita gela beroenak ere. Beroa errekuntza zantzuak dituen kanal itxuratik barrena hipokaustoan zehar zabalduko zen, baita estantzien arteko pareten hutsuneetan zehar ere. Fase honen adierazgarri nagusiak erdiko estantziako hegoaldeko sektorean aurkitutako pilae-ak, zein bigarren gelan kontserbatu den hipokaustodun zorua dira. Ezaugarri hauetako eraikinak K.o. I. mendearen hasieran hedatuko dira erromatar inperioko lurraldeetan (Fernandez \& García Entero, 1999, 142. or.); beraz, gunearen eraikuntza galtzadaren eraikuntza eta zerbitzuez hornitzearen kronologia eta funtzioarekin lotu liteke. Badirudi, testu honen erredakzio momentura arte ditugun material eta datuei erreparatuta behintzat, ezaugarri eta funtzio horiek II. mende amaiera arte egon izan zitekeela martxan.

Bigarren fasea terma azpiegituren abandonuarekin hasiko litzateke eta oraindik guztiz zehaztu gabeko erabilera produktiboren batekin lotuta egongo zen. Hipokaustoan zegoen hutsunea mota ezberdineko hondakinekin bete zuten (eraikuntza materialak, zeramikak, animalia hezurrak, etab.) eta horren gainaldea burdinaren eraldaketa gune gisa baliatu zuten. Azken jarduera horren adierazle izango dira 2018ko (eta neurri txikiago batean 2019ko) kanpainetan dokumentatutako zepa eta burdin meha aztarna ugariak. Sekuentzia estratigrafikoan oinarrituta, seguruenik, jarduera hauek antzinate berantiarrean kokatu beharko lirateke, K.o. III. eta IV. mendearen lehen erdian zehar.

\section{2020KO INDUSKETA ARKEOLOGIKOA}

Orotara 2020ko indusketa kanpainan $47 \mathrm{~m}^{2}$-ko eremua indusi da, termen eraikinaren hegoaldeko bi gunetan, hain zuzen ere. Induskatutako eraikineko guneen deskribapena errazte aldera, hegoaldetik iparraldera zenbakitzea erabaki da; horrela, hegoaldereneko espazioari 1 zenbakia esleitu zaio, 2.a opus caementicium-eko zorua duenari, 3.a opus spicatum lurzorukoari eta 4.a gune handienari (absidearenari, alegia).

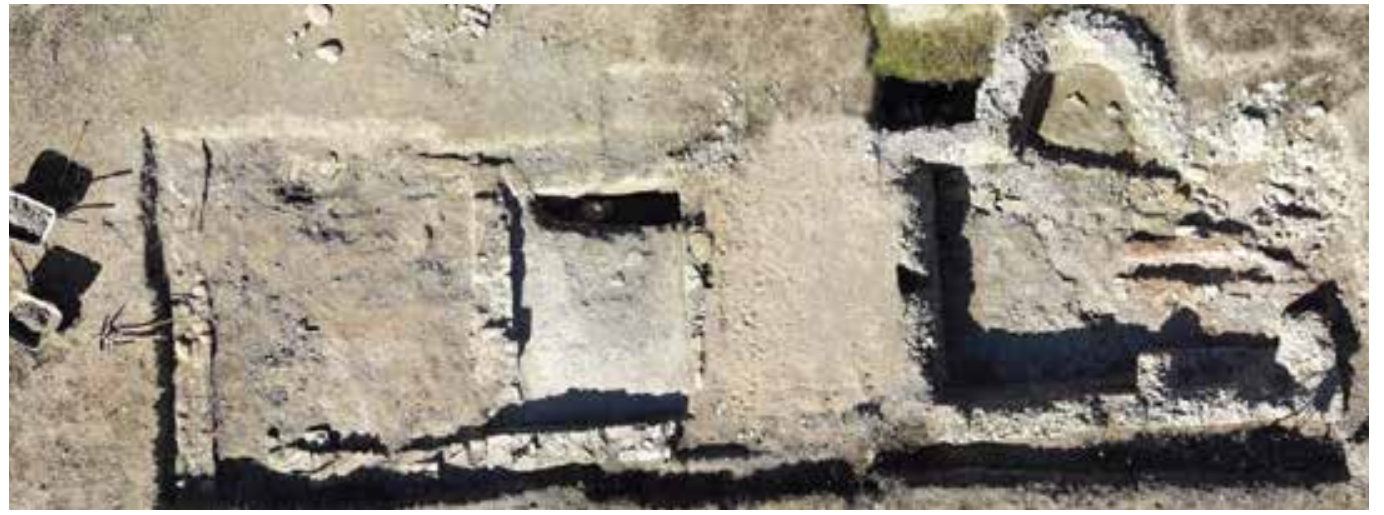

2. irudia. 2020ko indusketa kanpainan zehar ateratako aire argazkia. Egilea: J. Etxegoien.

Trabajos de Arqueología Navarra (TAN), 31-32, 2019-2020, 237-244 
Aurten esku hartutako 2. gelako zorua opus caementicium leundu batekin egina zegoela egiaztatu da, gainera gelaren ia azalera osoan zehar mantendu da gaur egun arte. Inguratzen dituen paretak gutxi landutako harriz eta morteroz eraikitakoak dira, mendebaldekoa salbu. Horretaz gain, harrizko pareta horietako batzuetan kolore arrosazko mortero entokadura arrastoak dokumentatu dira, paretak babestuta egongo zirenaren adierazle.

Eraikin bereko beste gela batzuen antzera, honetan ere mendebaldeko ertza izango da hondatuen erregistratu dena. Horma hori gainontzekoak baina kota baxuagoan topatu da eta inguru horretako zorua hautsita, berantiarragoa dirudien batekin estalia.

Bestalde, hegoaldeen kokatutako gunea, hots 1. gela, ezin izan da erabat indusi aurten, baina haren perimetroa mugatu da. Eraikin bereko beste pareten kontra jarritako landu gabeko harriz eta uharriz osatuta dago eta tartean ez du morterorik, soilik lurra. Hala ere, bi guneak tamainaz oso antzekoak dira, biek baitute $11,5 \mathrm{~m}^{2}$ inguruko azalera. Bertako aurkikuntza aipagarrienetako bat iparralderantz kokatuta dagoen gelaren pasabideko izkinan jatorriko tokian aurkitutako 22 teselak izan dira. Kareharrian zakar landutako teselak dira, guztiak kolore griskoak eta soilik $0,007 \mathrm{~m}^{2}$-ko mosaiko azalera osatzen dute. Inguruko betekinetan, ordea, oso tesela gutxi aurkitu dira (3-4 ale) eta guztiek aurrez adierazitako ezaugarri berdintsuak betetzen dituzte. Alabaina, lehen aldia da Artziko aztarnategian mota honetako gainazal bat topatu dela eta eraikinaren teknika eta kalitatea azpimarratzeko beste adierazle garrantzitsu bat izan daiteke.

Azkenik, indusketa eremuaren hegoaldeko mugan uharriz eta landu gabe harriz osatutako beste pareta bat dokumentatu da, aurtengo indusketa gunearen mugetatik harago, ekialde zein mendebaldera zabaltzen dena.

\section{ONDORIOAK}

2020ko indusketa kanpainarekin sarreran azaldutako informazioari honako datu hauek gehitzeko moduan gaude:

- Orain arte induskatutako gela guztietan bi fase nagusi daudela berresten da: lehenengoa instalazio termalena da, eta bigarrena ekoizpen metalurgikoarekin eta material baztertuen pilaketarena (fauna-hondarrak, zeramika, eraikuntza-materialak, etab.). Orain arteko informazioaren arabera, badirudi bi faseak erromatarren garaikoak direla: lehena K.o. I-II goi-inperioko garaikoa eta bigarrena, Antzinate Berantiarrean, hau da, K.o. III. mendekoa.

- Zirkuitu linealeko termak, gutxienez, 4 edo 5 egonaldi izan zitzakeen, oraindik ez baita ziur jakin hegoaldeko egonaldia lehen fasean edo ondorengo garai batean eraikiko zen.

- Sigi-sagan jarritako espazioen arteko sarbideak dokumentatu dira, hau da, aurrekoaren kontrako izkinan kokatuta daudenak. Antolamendu hori oso 
ohikoa izaten zen zirkuitu linealetan, giroaren tenperatura edo hezetasuna galtzen zuten aire-korronteak saihesteko. Pasabide batzuk 2. fasean tapatuta erregistratu dira, hala nola 3. eta 4. gelen arteko pasabidea (2019ko kanpainan industua).

- Hormetan erabilitako materialak eta eraikuntza-teknikak askotarikoak dira, nahiz eta obra garaikideak izan. Baliteke tekniken eta materialen arteko aldea eremu bakoitzaren funtzioarekin edo erabilerarekin lotuta egotea, baina hipotesi hori aztertzen joan beharko da. Orain arte, enkofratu bidez egindako hormak erregistratu dira, opus caementicium bidez (4. eta 3. gelak, eta 2. zenbakiko paretetako bat); bestetik, gutxi landutako harriekin egindakoak, morteroz lotuak (2. gela). Azkenik, landu gabeko harriak daude lurrez lotuta (1. gela eta indusketa eremutik harago doan horma).

- Lehen aldiz, opus tessellatum aztarnak erregistratu dira 1. eta 2. gelen arteko pasabidean. Azalera oso mugatua izan arren, tesela guztiak kolore berekoak dira eta itxura nahikoa dute. Mota honetako mosaikoak, I. eta II. mendeetan datatu ohi dira eta bat etorriko litzateke termen erabileraren fasearekin, hau $\mathrm{da}$, lehen garaiarekin. Pasabidean kokatzean, ezin izan da zehaztu gela osoan zabalduko litzatekeen edo pasabidearen eremura mugatuko litzatekeen.

- Oraingo kanpainan induskatutako geletan, egiaztatu ahal izan da horma batzuk kolore arrosako entokadura edo morteroz apainduta zeudela. Honek aurreko urteetan planteatutako teoria indartuko zuen, eraikinaren zenbait hormek estaldura izan zezaketelarena. Tratamendu horrek funtzio bikoitza izango luke, praktikoa (horma babestuz) eta aldi berean estetikoa.

\section{BIBLIOGRAFIA}

Agirre Mauleon, J., Martínez Txoperena, J. M. \& Puldain, J. (2012). Proyecto de prospección arqueológica en los términos municipales de Luzaide-Valcarlos, Orreaga-Roncesvalles, Auritz-Burguete, Erroibar-Valle de Erro y ArtzibarValle de Arce. Indusketa amaierako txostena (argitaratu gabea).

Balmelle, C. (2001). Les demeures aristocratiques d'Aquitaine. Société et culture de l'Antiquité tardive dans le Sud-Ouest de la Gaule. Bordeaux-Paris: Ausonius, "Mémoires » Aquitania, Suppl. 10.

Fernández Ochoa, C. \& García Entero, V. (1999). Las termas romanas del noroeste y de la Meseta Norte de Hispania. Los modelos arquitectónicos. Archivo Español de Arqueología, 72, 141-166.

García Entero V. \& Arribas Domínguez R. (2000). Los balnea de las villae y su proceso de monumentalización. En C. Fernandez Ochoa \& V. García Entero (eds.), II Coloquio Internacional de Arqueología en Gijon: termas romanas en el occidente del imperio (83-96. or.). Gijón: Vtp.

Garcia-Garcia, E. (2017). Geofisika tekniken karakterizazioa Euskal Herriko Antzinaroko aztarnategi arkeologikoetan (doktore tesia). UPV/EHU. 
Garcia-Garcia, E., Sala Bartroli, R. \& Ortiz-Quintana, H. (2017). Prospección geofísica del subsuelo del yacimiento romano de Arce. Presa de cola del embalse de Itoiz en el río Urrobi. T.M. de Valle de Arce (Navarra). Esku-hartze txostena (argitaratu gabea).

Iribarren Larrea, M. ${ }^{a}$ T., Larrea Irigoien, C. \& López-Mugartza Iriarte (coord.). (2019). Artzibarko Etxeak/ Las casas del Valle de Arce. Artzibar/Valle de Arce: Artzibarko Udala/ Ayuntamiento del Valle de Arce. 